\title{
Incidence of hypercalcaemia and primary hyperparathyroidism in relation to the biochemical profile
}

\author{
JS HARROP, JE BAILEY, JS WOODHEAD*
}

From the Department of Chemical Pathology, Derbyshire Royal Infirmary, Derby DE1 2QY, and Derby City Hospital, Derby DE3 3NE, and the * Department of Medical Biochemistry, Welsh National School of Medicine, Heath Park, Cardiff CF4 $4 X N$

SUMMARY Over a period of one year, 24500 patients underwent a biochemical profile investigation. Seven hundred and thirty-eight $(3 \%$ ) patients had a plasma calcium concentration of greater than $2.60 \mathrm{mmol} / \mathrm{l}$, and hypercalcaemia was confirmed in $49.8 \%$ of those subjects from whom a second fasting sample was received. Primary hyperparathyroidism and malignant disease were the two commonest causes of hypercalcaemia, occurring with equal frequency. The overall incidence of primary hyperparathyroidism in our population was $1: 680$. Over $75 \%$ of the patients with primary hyperparathyroidism appeared to have asymptomatic disease. The merits of including a plasma calcium determination in a biochemical profile would seem to depend particularly on the natural history of asymptomatic primary hyperparathyroidism.

In 1976 a multichannel analyser was commissioned in our Department and a plasma calcium determination has been included as one of the 14 tests performed on each blood sample submitted for a biochemical profile. In view of several reports describing increased recognition of hypercalcaemia following the introduction of biochemical screening ${ }^{1-4}$ we conducted over a period of one year a study of patients whose biochemical profile indicated hypercalcaemia. We have looked in particular at the causes of hypercalcaemia and the occurrence of primary hyperparathyroidism.

\section{Patients and methods}

The study year extended from 1 October 1978 to 30 September 1979. Samples from patients over the age of $15 \mathrm{y}$ on whom, at the clinician's request, a profile analysis was performed for the first time during this period were included. Plasma calcium was measured by the method of Gitelman ${ }^{5}$ modified for use on the Vickers M300 analyser. Our upper limit of normal for plasma calcium is $2.60 \mathrm{mmol} / 1$; this value, representing 2 SD above the mean, was confirmed in samples taken without venous stasis from 50 healthy, ambulant control subjects at the

Accepted for publication 27 July 1981 start of the study. When this level was exceeded the referring clinician was invited to submit a fasting sample taken from the patient without venous stasis for a second profile.

Plasma PTH was measured by immunoradiometric assay, ${ }^{6}$ using a predominantly C-terminal antiserum (BW211/41) and a reference preparation of human PTH (75/549) as standard. The sensitivity of the assay was $0 \cdot 15 \mu \mathrm{g} / \mathrm{l}$ and the between-batch coefficients of variation at $0.2 \mu \mathrm{g} / \mathrm{l}$ and $1.0 \mu \mathrm{g} / \mathrm{l}$ were $13 \%$ and $8 \%$ respectively. The upper limit for PTH in normocalcaemic subjects is $1 \mu \mathrm{g} / \mathrm{l}$. The tubular maximum reabsorptive capacity for phosphate relative to glomerular filtration rate $\left(T_{m} P / G F R\right)$ was estimated by the method and nomogram of Walton and Bijvoet. ${ }^{7}$ The reference range for $T_{m} P / G F R$ was defined in 30 normal subjects as 0.75 to $1.30 \mathrm{mmol} / \mathrm{l}$. The progress of patients with fasting hypercalcaemia was assessed, mostly by inspection of the clinical notes, at least six months after the date of their inclusion in the study.

\section{Results}

Biochemical profiles were performed on samples from 24500 patients. Of these $75 \%$ were from hospital inpatients, $19 \%$ were from outpatients and $6 \%$ were sent from patients seen by their family 
practitioners. Seven hundred and thirty-eight $(3 \%)$ patients had a plasma calcium concentration greater than $2.60 \mathrm{mmol} / \mathrm{l}$ on the first sample. A second fasting sample taken without venous statis was received from 404 of these 738 subjects and in 201 $(49.8 \%)$ the second plasma calcium determination was greater than $2.60 \mathrm{mmol} / \mathrm{l}$ and in $203(50.2 \%)$ was equal to, or less than, $2.60 \mathrm{mmol} / \mathrm{l}$.

PATIENTS WITH HYPERCALCAEMIA

The distribution of plasma calcium concentrations in the 738 patients identified as hypercalcaemic from the first casual sample is shown in histogram form in Fig. 1. This Figure also shows those patients from

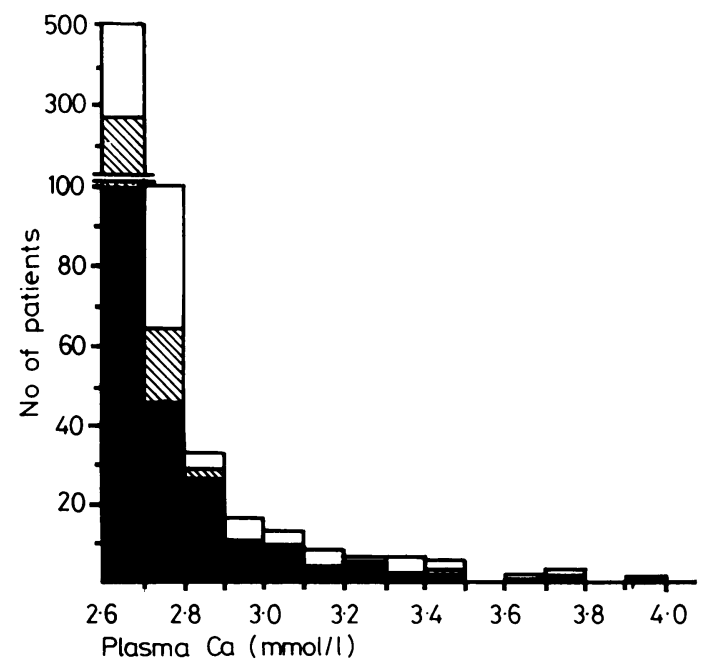

Fig. 1 Distribution of plasma calcium concentrations (a) in 738 patients whose profile indicated hypercalcaemia from a first "casual" sample, (b) in 404 of these patients in whom a second fasting sample was analysed (hatched and solid areas), (c) in 201 patients in whom hypercalcaemia was confirmed in the fasting sample (solid area).

whom a second and fasting sample was received, and of these the patients with fasting hypercalcaemia. The presenting plasma calcium concentration was between 2.61 and $2.70 \mathrm{mmol} / \mathrm{l}$ in 272 patients from whom a second and fasting sample was obtained. The plasma calcium concentration in the second sample was raised in $37 \%$ of these patients. For those patients with presenting plasma calcium concentrations between $2 \cdot 71$ and $2 \cdot 80,2 \cdot 81$ and $2 \cdot 90$, and greater than $2.90 \mathrm{mmol} / \mathrm{l}$, the proportions who were hypercalcaemic according to the second fasting sample were $72 \%, 93 \%$, and $98 \%$ respectively. Thus, of 39 patients with a plasma calcium concentration of greater than $2.90 \mathrm{mmol} / \mathrm{l}$, hypercalcaemia was confirmed on the second occasion in all but one.

The causes of hypercalcaemia in the 201 patients in whom this diagnosis was confirmed in the second sample are shown in Fig. 2. The commonest causes were hyperparathyroidism, occurring in $30.3 \%$ of the patients, and malignant disease occurring in $29.4 \%$. The reason for hypercalcaemia could not be determined with certainty in $24.9 \%$ of the patients; this group of 50 subjects included 12 patients who died and 23 patients with inadequate follow-up data. In $11.4 \%$, hypercalcaemia was attributed to treatment with thiazide diuretics; these patients had mild hypercalcaemia only, many were normocalcaemic at subsequent examinations, and there was no evidence of hypophosphataemia in this group. Mean plasma albumin was slightly, but not significantly greater in the thiazide-treated subjects than in normal subjects $(45.8 \pm 3.3 \mathrm{~g} / 1 v 44.7 \pm 2.6 \mathrm{~g} / 1$ (mean \pm 1 SD)). Of our patients with hypercalcaemia, $4 \%$ were taking vitamin D preparations.

Of the 59 patients with malignant disease and hypercalcaemia, 21 had carcinoma of the bronchus. The primary tumour sites in the remaining patients were breast 10 ; kidney 5 ; uterus/cervix 4 ;large intestine 3 ; larynx 2 ; myeloma 2 ; ovary 1 ; bladder 1 ; oesophagus 1 ; malignant melanoma 1 ; mesothelioma 1 ; and fibrosarcoma of bone 1 . In six patients the primary site was unknown. Of these 59 patients with malignancy and hypercalcaemia, 50 have died. The mean survival time of these 50 patients was $12 \mathrm{wk}$ from the date of discovery of hypercalcaemia (range 1-39 wk).

PATIENTS WITH PRIMARY

HYPERPARATHYROIDISM

The diagnosis of primary hyperparathyroidism was made in 61 patients $(30.3 \%)$ with hypercalcaemia recorded in the year of the study. This diagnosis was based on the demonstration of fasting hypercalcaemia accompanied by inappropriate plasma PTH concentrations (PTH $>0.4 \mu \mathrm{g} / \mathrm{l}$; see Fig. 3 ) with no evidence for other causes of hypercalcaemia developing before review at least six months later. Fasting plasma phosphate concentrations were significantly lower in the hyperparathyroid subjects than in normal control subjects $(0.79 \pm 0.13 \mathrm{mmol} / \mathrm{l} v$ $1.00 \pm 0.15 \mathrm{mmol} / \mathrm{l}(\mathrm{p}<0.001))$. Measurement of $T_{m} P / G F R$ was also made in 44 of the 61 patients, in 42 of whom the value was less than the lower limit of normal of $0.75 \mathrm{mmol} / \mathrm{l}$ (mean $0.54 \mathrm{mmol} / \mathrm{l}$; range 0.32 to $0.71 \mathrm{mmol} / \mathrm{l}$ ), with low normal values of 0.76 and $0.78 \mathrm{mmol} / 1$ in the other two patients (Fig. 3). In 11 patients, whose fasting plasma calcium concentration was mildly raised $(2 \cdot 61-2.72 \mathrm{mmol} / \mathrm{l})$, plasma PTH concentration varied from 0.48-1.70 $\mu \mathrm{g} / \mathrm{l}$. All 11 patients also had a low $\mathrm{T}_{\mathrm{m}} \mathrm{P} / \mathrm{GFR}$ 


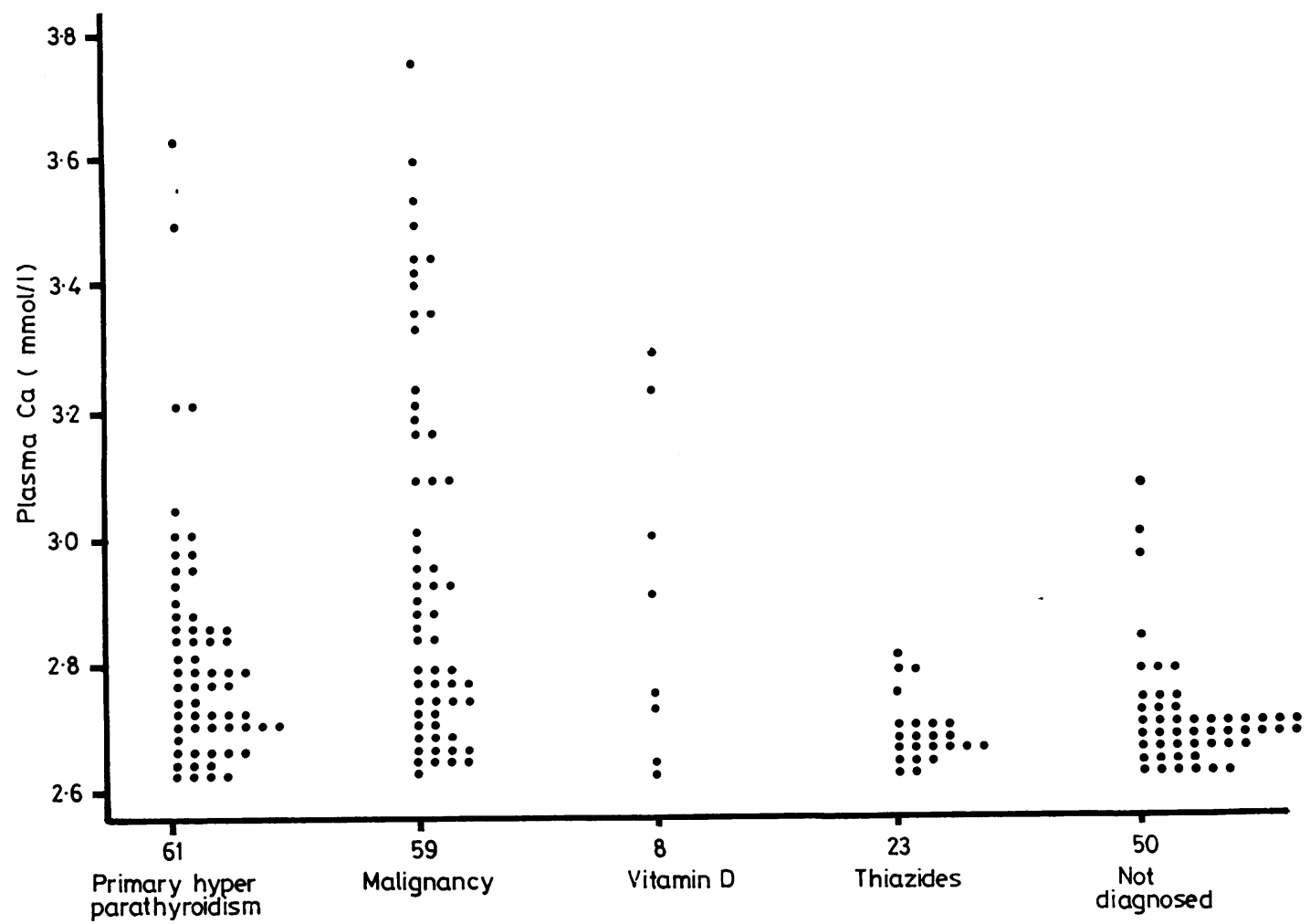

Fig. 2 Distribution of fasting plasma calcium concentrations in relation to aetiology in 201 patients with hypercalcaemia. The number of patients in each group is also shown.

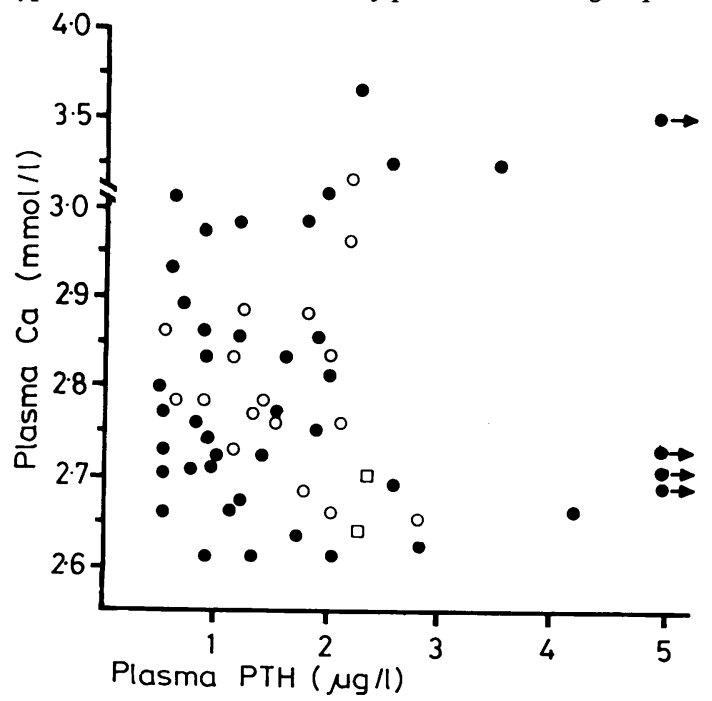

Fig. 3 Relation between plasma calcium and PTH concentrations in 61 patients with primary hyperparathyroidism recorded over the one year study period. $=42$ patients in whom $T_{m} P / G F R$ was low, and $\square=2$ patients in whom $T_{m} P / G F R$ was normal. (mean $0.56 \mathrm{mmol} / \mathrm{l}$; range $0.39-0.68 \mathrm{mmol} / \mathrm{l}$ ). This observation provides further evidence for increased PTH activity in these mildly hypercalcaemic subjects in whom the diagnosis of "inappropriate" PTH secretion depends so much on the certainty that true hypercalcaemia exists.

Although hyperparathyroidism was diagnosed in 61 patients, this diagnosis had been made prior to the survey in 25 patients, whose biochemical monitoring continued into the survey year. Thirtysix patients with hyperparathyroidism presented for the first time during the survey year. Samples were received from 24500 patients in this year and thus the incidence of hyperparathyroidism in our "laboratory referred" population as a whole is 1 in 680 . Of the 36 patients, 21 were first seen as outpatients, 5 as inpatients, 3 as psychiatric inpatients and 7 were referred by family practitioners. There were 23 female patients and 13 male patients. Age-specific incidences of hyperparathyroidism, calculated from the age distribution of all patients undergoing a profile analysis are shown in the Table. The highest number of cases appeared in the 50-59 yr age group, giving a peak incidence of 1 in 335. The Table also shows the differences in the incidence of 
Age distribution of 24500 new patients on whom a profile analysis was performed, and of newly diagnosed hyperparathyroid subjects, showing age-specific incidences; and patient distribution of the same individuals at first identification of hypercalcaemia

\begin{tabular}{|c|c|c|c|c|c|c|c|c|}
\hline & \multicolumn{5}{|c|}{ Age distribution (yr) } & \multicolumn{3}{|c|}{ Patient distribution } \\
\hline & $<50$ & $50-59$ & $60-69$ & $70-79$ & $>79$ & Inpatients & Outpatients & $\begin{array}{l}\text { General } \\
\text { practice }\end{array}$ \\
\hline \multirow{5}{*}{$\begin{array}{l}\text { No of patients } \\
\% \text { of total } \\
\text { No with hyperparathyroidism } \\
\text { Incidence of } \\
\text { hyperparathyroidism (1: }\end{array}$} & 7347 & 4013 & 4969 & 5287 & 2884 & 18375 & 4655 & 1470 \\
\hline & 30 & 16 & 20 & 22 & 12 & 75 & 19 & 6 \\
\hline & 6 & 12 & 7 & 9 & 2 & 21 & 8 & 7 \\
\hline & & & & & & & & \\
\hline & 1225) & 335) & 711) & 588) & 1445) & 875) & 582) & 210) \\
\hline
\end{tabular}

hyperparathyroidism according to whether the patient wasseen in hospital or by a family practitioner when hypercalcaemia was first identified.

Of the 36 patients with hyperparathyroidism first diagnosed in the year of the study, only 8 had clinical findings reasonably attributable to hypercalcaemia; 4 had renal disease (calculi/nephrocalcinosis), 2 had metabolic bone disease, 1 had depression and 1 presented with acute hypercalcaemia. Two further subjects were long-stay psychiatric patients. In the remaining 26 patients the primary diagnosis included a variety of general medical and surgical conditions. Eleven patients had hypertension.

\section{Discussion}

Many chemical pathology laboratories in recent years have added some form of biochemical profile to their routine service. This simplifies work organisation within the laboratory, but the clinical usefulness of the approach has been debated.$^{8-10}$ Inclusion of a plasma calcium determination in the profile leads both to an increase in the number of patients identified as hypercalcaemic ${ }^{211} 12$ and in the diagnosis of hyperparathyroidism. ${ }^{1-3}$ Over a one-year period we have found that hypercalcaemia occurred in $3.0 \%$ of patients undergoing a biochemical profile, and this finding was confirmed in $49.8 \%$ of these patients from whom a second fasting sample, taken without venous stasis, was received. The importance of a second, or preferably repeated, plasma calcium measurement for correct definition of hypercalcaemia is well recognised. It is interesting to note that a study of hypercalcaemia in a health screening programme 4 found that $50 \%$ of subjects with an initial result indicating hypercalcaemia were normocalcaemic as judged by a second fasting sample taken without stasis. Other hospital-based studies have indicated a higher proportion of subjects in whom hypercalcaemia is confirmed $\left(\mathbf{7 0} \% \mathrm{1}^{13}\right.$ and $84 \% 14$ ), but the cut-off points and the populations examined vary in these reports. Whether patients need necessarily be fasting for correct definition of calcium status is perhaps debatable. We certainly found no significant difference between casual and fasting plasma calcium concentration in our patients with confirmed hypercalcaemia, but fasting is essential for proper interpretation of plasma phosphate concentrations.

The cut-off point of $2.60 \mathrm{mmol} / \mathrm{l}$ for plasma calcium used in our study is the upper limit in normal use in this laboratory and is defined as 2SD above the mean $(2.40 \mathrm{mmol} / \mathrm{l})$ for healthy subjects. We recognise that on this basis $2.3 \%$ of normal subjects will have a concentration above $2.60 \mathrm{mmol} / \mathrm{l}$, but this figure cannot be applied directly to our patient population as the mean plasma calcium concentration for all patients throughout the year was 2.34 $\mathrm{mmol} / \mathrm{l}$. It is perhaps more realistic to state that as we found hypercalcaemia in $3.0 \%$ of patient samples then our cut-off point simply represents the 97th percentile of the patient population. We did not adjust plasma calcium for the plasma albumin concentration in this study as both the validity of this manoeuvre, ${ }^{1516}$ and its ability to predict the ionised calcium concentration ${ }^{17} 18$ have been debated. The value of the albumin-adjusted calcium concentration in defining borderline hyperparathyroidism has also been specifically questioned, ${ }^{19}$ and in this situation direct measurement of ionised calcium is the preferred measurement. ${ }^{19} 20$ We would further suggest that although our between-batch precision for calcium determination is $1.9 \%$, a level of analytical variation typical of many laboratories using automated techniques, this itself makes the adjustment of plasma calcium concentrations to levels slightly above or below $2.60 \mathrm{mmol} / \mathrm{l}$ a very dubious exercise. Flynn et al ${ }^{21}$ indicated that the contribution of between batch analytical error to the normal range was as high as $29 \%$ in the case of calcium.

This problem of borderline results is further compounded by the fact that within-person variation for plasma calcium is much less than the so-called "normal range," which encompasses both analytical and biological variation. Data obtained in our laboratory show that over a five-week period, each of 10 normal subjects maintained the plasma calcium concentration within $\pm 0.1 \mathrm{mmol} / \mathrm{l}$ of the 
mean of 10 separate determinations over the observation period. All these considerations serve to emphasise the problems in interpreting borderline results, and the desirability for substantial improvements in techniques of calcium analysis, ${ }^{22}$ and the manner in which normal ranges are derived and presented.

Our results suggest that malignant disease and hyperparathyroidism are equally common causes of hypercalcaemia in a general hospital population. Other reports of hypercalcaemia in hospital populations, although drawing attention to the frequency of hyperparathyroidism, have found malignancy to be the commonest cause of profile hypercalcaemia. ${ }^{213}$ These studies were restricted to inpatients only, and the results therefore are not strictly comparable to our findings. Not unexpectedly, hyperparathyroidism is the commoner cause of hypercalcaemia in population screening studies. ${ }^{411}$ Our follow-up data in patients with hypercalcaemia and malignancy revealed a depressingly bad prognosis. Conceivably some of these patients may have had coexistent hyperparathyroidism, ${ }^{23}$ but this possibility was not pursued in this group of patients.

Two recent studies have drawn attention to a dramatic increase in the diagnosis of hyperparathyroidism when a plasma calcium determination is included in a profile investigation. ${ }^{24}{ }^{25}$ Large series of patients with symptomatic hyperparathyroidism have been reported from specialist centres over the years, but in the present study findings have not been coloured by referral patterns, except in so far as our population is "laboratory-based." This almost certainly explains the much higher proportion of asymptomatic and apparently mild disease in our study than in previously reported series. Similar results, however, were reported from a study in Birmingham, ${ }^{25}$ which was also conducted as a follow-up of profile hypercalcaemia.

Knowledge of the total number of new patients undergoing a profile examination allows us to estimate the incidence of hyperparathyroidism in our population as at least 1:680. Age-related figures, however, reveal that the condition is at least as common in the 50-59 yr age-group as in patients over 70 yr. Mundy et al $^{25}$ suggested that hyperparathyroidism was commonest in women over $70 \mathrm{yr}$, but the age distribution of their screened population was not stated. It is interesting to note that in a population screening programme Christensson et al ${ }^{4}$ found a higher frequency of $1: 278$ in a population whose maximum age was $63 \mathrm{yr}$. This agrees very closely with the frequency with which we identified hyperparathyroidism in patients being seen by their family practitioners. Our patient numbers are rather small, however, and more extensive studies are required to define more closely age-specific incidences.

Purnell et $a l^{26}$ have suggested that surgery will be required in $20 \%$ of patients with "biochemical" hyperparathyroidism during a follow-up period of five years. The need for more detailed knowledge of the natural history of hyperparathyroidism, before definitive recommendations concerning its management can be made, has been discussed. ${ }^{27-29}$ Likewise, in the light of present knowledge, the value of including a plasma calcium determination in a profile test is not easy to assess. The costs of measuring calcium in all profile samples in our laboratory over the year of the study was $\mathbf{1 4 0 7 0}$. This figure assumes a working life for the Vickers M-300 analyser of seven years, and includes appropriate apportionments of installation and capital equipment costs, running costs and operator time, Therefore the cost per newly diagnosed hyperparathyroid patient is $£ 113$, and per newly diagnosed asymptomatic patient $£ 145$. If, however, a calcium determination is withdrawn from the screening profile, then firstly, apportioned capital moneys would not be recouped and secondly, the laboratory would need to provide an alternative analytical system for calcium measurement on a discretionary basis. Thus detailed costings rapidly become very nebulous. A specific request for a calcium determination would probably be made on patients with malignant disease were this analysis not included in a profile and therefore we have ignored this group of patients in discussing the case for profile calcium determinations. The benefits of including a calcium determination would appear to depend very heavily on the clinical significance of asymptomatic primary hyperparathyroidism and this is largely unknown. Close attention to the results of plasma calcium determinations produced by an increasing number of laboratories adopting profile type analyses will help to define the true frequency of this condition and its natural history.

We thank Mr G King and Mr C Taylor for expert technical assistance, Mr S Garner for valuable help with computer programming and Mrs $\mathrm{K}$ Lydall and Joanne Williams for secretarial support. Dr Geoffrey Walker made many useful comments. We also thank many clinical colleagues and family practitioners in Derby for allowing us to review patients under their care.

\section{References}

${ }^{1}$ Haff RC, Black WC, Ballinger WF. Primary hyperparathyroidism: changing clinical, surgical and pathologic aspects. Ann Surg 1970;171:85-92.

2 Mays ET, Weakley SD. Serum multichannel autoanalysers 
in the detection of hypercalcaemia and hyperparathyroidism. Surg Gynecol Obstet 1971;131:603-8.

${ }^{3}$ Boonstra CE, Jackson CE. Serum calcium survey for hyperparathyroidism: results in 50,000 clinic patients. Am J Clin Pathol 1971 ;55:523-6.

${ }^{4}$ Christensson T, Hellstrom K, Wengle B, Alveryd A, Wikland B. Prevalence of hypercalcaemia in a health screening in Stockholm. Acta Med Scand 1976;200: 131-7.

5 Gitelman HJ. An improved automated procedure for the determination of calcium in biological specimens. Anal Biochem 1967;18:521-31.

- Addison GM, Hales CN, Woodhead JS, O'Riordan JLH. Immunoradiometric assay of parathyroid hormone. $J$ Endocrinol 1971;49:521-30.

' Walton RJ, Bijvoet OLM. Nomogram for derivation of renal threshold phosphate concentration. Lancet 1975; ii:309-10.

${ }^{8}$ Wilson JMG. Current trends and problems in health screening. $J$ Clin Pathol 1973;26:555-63.

${ }^{9}$ Whitehead TP, Wootton IDP. Biochemical profiles for hospital patients. Lancet 1974 ; ii:1439-43.

${ }^{10}$ Holland WW. Screening for disease: taking stock. Lancet $1974 ;$ ii :1494-7.

${ }^{11}$ Keating FR Jr, Jones JD, Elveback LR. Distribution of serum calcium and phosphorus values in unselected ambulatory patients. J Lab Clin Med 1969;74:507-14.

${ }^{12}$ Heedman P-A, Stenstrom G. Clinical findings in patients with hypercalcaemia. Acta Med Scand 1973;193:167-73.

${ }^{13}$ McLellan G, Baird CW, Melick R. Hypercalcaemia in an Australian hospital adult population. Med J Aust 1968; 2:354-6.

1 Stenstrom G, Heedman P-A. Clinical findings in patients with hypercalcaemia. Acta Med Scand 1974;195:473-7.

${ }^{15}$ Payne RB, Little AJ, Williams RB, Milner JR. Interpretation of serum calcium in patients with abnormal serum proteins. $\mathrm{Br}$ Med $J$ 1973;4:643-6.

16 Pain RW, Rowland KM, Phillips PJ, Duncan BMcL. Current "corrected" calcium concept challenged. $\mathrm{Br}$ Med J 1975;4:617-9.

17 Conceicao SC, Weightman Doris, Smith PA, Luno J, Ward MK, Kerr DNS. Serum ionised calcium concentration: measurement versus calculation. $\mathrm{Br}$ Med J
$1978 ; \mathrm{i}: 1103-5$.

18 Ladenson JH, Lewis JW, Boyd JC. Failure of total calcium corrected for protein, albumin, and $\mathrm{pH}$ to correctly assess free calcium status. J Clin Endocrinol Metab 1978;46:986-93.

19 Larsson L, Ohman S. Serum ionized calcium and corrected total calcium in borderline hyperparathyroidism. Clin Chem 1978;24:1962-5.

${ }^{20}$ Muldowney FP, Freaney R, McMullin JP, et al. Serum ionized calcium and parathyroid hormone in renal stone disease. Quart J Med 1976;45:75-86.

${ }^{21}$ Flynn FV, Piper KAJ, Garcia-Webb P, McPherson K, Healy MJR. Biological and analytical variation of commonly determined blood constituents in healthy blood donors. Clin Chim Acta 1976;70:179-89.

${ }^{22}$ Barrett AE, Cameron SJ, Fraser CG, Penberthy LA, Shand KL. A clinical view of analytical goals in clinical biochemistry. J Clin Pathol 1979;32:893-6.

${ }^{23}$ Drezner MK, Lebovitz HE. Primary hyperparathyroidism in paraneoplastic hypercalcaemia. Lancet 1978;i:1004-6.

${ }^{24}$ Heath H, Hodgson SF, Kennedy MA. Primary hyperparathyroidism: incidence, morbidity, and potential economic impact in a community. $N$ Engl J Med 1980; 302:189-93.

${ }^{25}$ Mundy GR, Cove DH, Fisken R, Somers S, Heath DA. Primary hyperparathyroidism: changes in the pattern of clinical presentation. Lancet 1980; i 1317-20.

${ }^{26}$ Purnell DC, Scholz DA, Smith LH, et al. Treatment of primary hyperparathyroidism. Am J Med 1974;56: 800-9.

${ }^{27}$ Coe FL, Favus J. Does mild asymptomatic hyperparathyroidism require surgery? $N$ Engl $J$ Med 1980;302: 224-5.

28 Anonymous. Diagnosis and treatment of primary hyperparathyroidism. Lancet $1980 ; 1: 1339-40$.

29 Anonymous. Mild asymptomatic hyperparathyroidism. Br MedJ 1980;iii:174-5.

Requests for reprints to: Dr JS Harrop, Consultant Chemical Pathologist, Derby City Hospital, Uttoxeter Road, Derby DE3 3NF, England. 